\title{
Um ensaio sobre as concepções de professores de Matemática: possibilidades metodológicas e um exercício de pesquisa
}

\author{
Antonio Vicente Marafioti Garnica
}

Universidade Estadual Paulista

\section{Resumo}

Este artigo tem como tema principal as concepções dos professores de Matemática. Considerando o termo "concepção" a partir do pragmatismo de Peirce, elabora-se um conjunto de parâmetros metodológicos - chamado de "método indireto" - a ser aplicado no estudo das concepções de professores de Matemática. Trata-se, em sintese, de investigar as concepções dos professores interpelando-os não sobre suas crenças, mas sobre suas práticas. Fundamentando essa abordagem indireta e explicitando-a em sua natureza qualitativa, o artigo segue apresentando, como exemplo, um exercício desse "método indireto": um estudo sobre os critérios que os professores utilizam quando escolhem livros-texto para sua sala de aula, abordando, conseqüentemente, quais concepções de Matemática e de seu ensino e aprendizagem tais critérios desvendam. Partindo de depoimentos de professores de Matemática, o estudo indica que os professores agem com certa independência quando escolhem os materiais utilizados em suas atividades docentes. Buscam, ao mesmo tempo, apoio em uma vasta gama de livros didáticos, desconsiderando as particularidades de cada obra e as abordagens e perspectivas defendidas por seus autores. Embora submetam-se ao livro didático - considerado uma referência legítima e segura -, os professores o subvertem, buscando adequá-lo ao que consideram correto. Dessa constatação, algumas das concepções dos professores podem ser realçadas: o aluno, via de regra, é avaliado e classificado pelas lacunas que apresenta em relação aos conteúdos. Dessa postura, segue a valorização da precedência lógica dos conteúdos, de sua apresentação linear, e a defesa de "pré-requisitos" que viabilizariam o ensino e, conseqüentemente, implicam a legitimidade de aulas predominantemente expositivas.

\section{Palavras-chave}

Concepções - Formação de professores - Educação Matemática Livros didáticos de Matemática. 


\section{An essay on the conceptions of Mathematics teachers: methodological possibilities and a research exercise}

Antonio Vicente Marafioti Garnica

Universidade Estadual Paulista

Contact:

Antonio Vicente Marafioti Garnica

UNESP - Depto de Matemática

Av. Luis E. C. Coube, s/n.

17033-360 - Bauru - SP

e-mail: vgarnica@fc.unesp.br

\section{Abstract}

This article has as its main theme the conceptions held by Mathematics teachers. By understanding the term "conception" on the basis of Peirce's pragmatism, a set of methodological parameters are produced - denominated "indirect method" - to be applied in the study of Mathematics teachers' conceptions. In summary, we want to investigate teachers' conceptions asking them not about their beliefs, but about their practices. After presenting the foundations of this indirect approach, and of making explicit its qualitative nature, the study proceeds to exemplify it with an exercise of this "indirect method", a study about the criteria used by teachers to select textbooks for their classes, thereby dealing with the conceptions of Mathematics and of its teaching and learning that such criteria disclose. Based on testimonies of Mathematics teachers, the study suggests that teachers act with some independence when they choose the materials to be used in their classes. At the same time, they draw from a wide range of textbooks, disregarding the specificities of each work and the approaches and perspectives espoused by their authors. Although they submit to textbooks - regarded as a legitimate and reliable source - teachers subvert them, trying to making them adequate to what they consider correct. From this observation, some of the teachers' conceptions can be highlighted: the pupil is usually evaluated and classified according to their deficiencies with respect to the contents. From this position follows the high value placed upon the logical precedence of the contents, their linear presentation, and the defense of "prerequisites" that would make teaching possible and, consequently, imply the legitimacy of predominantly expository classes.

\section{Keywords}

Conceptions - Teacher education - Mathematical education Mathematics textbooks. 
Certa vez, pretendendo desenvolver um trabalho de pesquisa sobre as dificuldades enfrentadas por estudantes da escola fundamental, optamos - eu e uma orientanda - por focar o assunto "resolução de equações de primeiro grau" e, a partir disso, distribuir questionários em escolas da região. Uma das perguntas do questionário - se não todo ele era extremamente direta. Pensávamos que se iniciássemos a aproximação com cada sala de aula explicando habilmente (nós, professores, sempre nos consideramos hábeis para explicar e é bastante comum que atribuamos os problemas de ensino, todos, a problemas de comunicação) o que era uma equação do primeiro grau, os estudantes recapitulariam suas ações em relação a esse conteúdo e, numa linguagem minimamente coerente (nós, professores, sempre esperamos dos alunos uma linguagem minimamente coerente), explicitariam suas dificuldades. Supusemos, na verdade, que os alunos reconheceriam seguramente suas dificuldades de modo a explicitá-las para que, a partir dessa explicitação, pudéssemos indicar (para os estudantes e seus professores) modos mais adequados de tratar os problemas que, certamente, detectaríamos durante a - e como resultado da - investigação. A natureza inadequada dessa abordagem deve ser creditada tanto à nossa falta de experiência com instrumentos de coleta de dados quanto, de um modo geral, à falta de clareza sobre o que era, realmente, "fazer pesquisa": ingenuidades compreensíveis, mas de muitas formas imperdoáveis. As respostas dos estudantes ao questionário foram as mais diversas possíveis e uma delas, em especial, talvez pelo tom pitoresco, disparou uma questão de pesquisa que até hoje nos persegue.

- "Você tem dificuldades para resolver equações de primeiro grau? Se sim, quais?", foi uma das perguntas.

- "Sim. Inclusive todas"; foi uma das respostas.

Que dificuldades seriam essas que sequer podiam ser explicitadas, listadas, ditas de modo coerente? A linguagem não dava conta de explicitar o que ocorre quando, confrontado com uma equação de primeiro grau, o aluno é chamado a agir? As dificuldades estavam no domínio do indizível, no campo do interdito?

Não. Certamente não teríamos respostas diretas a perguntas tão amplas, mas as fazer (do mesmo modo como compusemos aquele questionário) explicitava - agora sabemos - algumas de nossas concepções como professorespesquisadores: concepções sobre o estudante, sobre a Matemática, sobre a escola, sobre os professores, sobre o ensino de Matemática, sobre dificuldades de aprendizagem, sobre linguagem etc. 0 que nos deu um caminho para investigar nossas próprias concepções sobre esses tantos elementos que nos são cotidianos não foi o nosso discurso já pronto sobre essas concepções, mas o modo como essas concepções se manifestaram em nossa prática efetiva. Nossa intenção de focar um objeto para investigar e proceder como procedíamos até então também indicava uma nossa concepção de pesquisa, de ciência, de método. Com esses questionamentos, iniciamos um percurso de procurar como investigar "concepções".

Nossa prática no cotidiano das escolas e de seus entornos nos dá elementos a partir dos quais articulamos falas sobre esse cotidiano. Se nos perguntam: "qual sua concepção sobre Matemática?", todo um leque de frases prontas nos surge. São frases pré-elaboradas, freqüentes no nosso dia-a-dia, nas documentações oficiais, nos projetos pedagógicos, nos discursos competentes dos técnicos e pesquisadores. Frases que insistentemente transitam nos corredores das escolas e tornam-se jargões, toadas que vão perdendo seu encanto motivador e tornam-se sentenças sem significado que só atestam nossa capacidade de nos reconhecermos como membros de uma determinada comunidade que nos aceita por repetirmos, insistentemente, esses mantras obrigatórios. Nos estudos de crítica literária, há uma expressão para situações dessa natureza: "desaparição pletórica”. Algo (no caso, os significados, o encanto motivador) 
desaparece por conta da repetição abusiva, do uso insistente e indiscriminado. A desaparição pletórica dos significados em nossos mantras educacionais oficiais: também esse um bom tema para uma investigação.

No entanto, voltemos às nossas frases. Nós as reproduzimos, as divulgamos, as potencializamos sem que nada em nossa prática seja efetivamente alterado: meros discursos que oficializamos e cujos limites e validade não questionamos. É imperativo reproduzi-los, perpetuá-los. Fazem parte do arsenal de posturas que nos permite ocupar a posição que ocupamos. Nas salas de professores, nos corredores, em nossas salas de aula, com nossos alunos, quando podemos nos liberar do discurso "oficial", nossa prática permanece ilesa, impermeável àquele jargão que ajudamos a propagar. Em algumas situações, quando livres do perigo de uma certa repressão, alteram-se os mantras que nos identificam como membros do clube. Comunidades são grupos de discurso. Bem ao gosto dos matemáticos, diríamos que comunidades não são meros conjuntos de pessoas: são estruturas algébricas - vibrantes, portanto -, de pessoas em suas relações discursivas. Inscrevo-me numa determinada comunidade porque compartilho de seus discursos, crio e sustento suas verdades, suas regras, e vivo segundo os modos permitidos pelas verdades e regras - discursos - que crio e faço funcionar numa engrenagem que reconheço e que me torna o que sou no grupo. Se há a comunidade dos mantras, dos discursos oficialmente reconhecidos, há também a comunidade dos que subvertem tais discursos. A comunidade de subversores de mantras, aparentemente - insistindo: aparentemente - em estado de espírito paradoxal, convive harmoniosamente com os, digamos, mantenedores dos mantras. Entretanto, não há, dicotomicamente, duas comunidades: não somos um, somos vários.

Para alguns, esse não é, certamente, um quadro alentador, mas nos parece um quadro realista. Como, então, aceitando essa configuração do cenário, investigar as concepções que vigoram, efetivamente, nas nossas escolas, em nossas salas de aula, nos documentos e projetos - palcos em que coexistem várias comunidades? Com essa questão inicia-se nossa busca sobre um método que nos permita ter as "concepções" como tema central num processo de investigação.

\section{Concepções e ações}

0 tema concepções não é novo na literatura da pesquisa educacional. Há inúmeros trabalhos em Educação Matemática e em Ensino de Ciências focando, principalmente, "mudança de concepções”. De um modo geral, a abordagem a esse tema sofre de um malfadado círculo vicioso: identificar ou promover mudanças nas concepções implica detectarmos, a priori, as concepções anteriores à mudança. Há, nessa afirmação, inúmeros pontos de fuga, mas ressaltamos, dentre eles, um elemento a ser considerado: são as concepções estáveis de modo a se deixarem identificar tão facilmente e tão mansamente serem sujeitáveis a alterações?

Muitos autores pensam que sim. Sofrem de uma síndrome facilmente detectável: conhecida determinada concepção sobre determinado fenômeno, implementa-se uma ou várias práticas "alternativas" (sejam cursos, projetos, materiais manipulativos etc.) plasmadas em concepções diferenciadas, julgadas "melhores"; avaliam-se a elaboração, a implementação, o desenvolvimento e os resultados de tais práticas "alternativas", comprovando-se - ou não - por fim, a alteração das concepções. Concepções são tidas como "coisas", e muitas das pesquisas sobre essas "coisas” julgadas estáticas e facilmente detectáveis podem ser comparadas aos testes experimentais que tanto sucesso fazem no mundo da propaganda: um branco amarelado (as concepções anteriores), um recipiente com potente sabão (as práticas "alternativas"), o branco mais branco (a nova concepção, via de regra qualitativamente superior em relação à anterior).

Não há, entretanto, tal concepção estática. Como qualquer percepção que temos do 
mundo, as concepções estão em constante mutação, num processo não linear que alterna alterações e permanências. Nossa visão acerca de algo está radicada nas nossas percepções, no que sentimos do mundo, no que sentem do mundo as pessoas com as quais convivemos, de como elaboramos essas percepções e as tornamos operacionalizáveis para continuarmos vivendo e convivendo (vivendo com outros). Isso é próprio do que poderíamos chamar "processo de formação", ainda que tal processo não tenha um objetivo claro e definido previamente, pois também seus objetivos vão se alterando durante o processo, mantendo algumas características e revertendo outras que até então julgávamos estabelecidas. Martin Heidegger (1993), o filósofo alemão do Ser e tempo, já nos ensinava que o humano é, ao mesmo tempo, mais do que é e menos do que é: é mais, pois é possibilidade de ser; mas é menos, pois o mundo o obriga a fazer escolhas dentre aquelas várias possibilidades.

Se pretendemos investigar "concepções", estamos, pois, num meio extremamente fluido, dinâmico, inconstante. Seria possível, porém, ainda que cientes dessas limitações, procurarmos por algumas zonas de estabilidade no que temos chamado "concepções"? Cremos que sim.

Vamos considerar como "concepções" os "algos” (crenças, percepções, juízos, experiências prévias etc.) a partir dos quais nos julgamos aptos a agir. Concepções são, portanto, suportes para a ação. Mantendo-se relativamente estáveis, as concepções criam em nós alguns hábitos, algumas formas de intervenção que julgamos seguras. Essa vinculação entre concepção e ação não é nova nem pode ser creditada a uma única teoria. Vários teóricos trataram do tema da ação, das práticas humanas e de seus fundamentos. Segundo Romulo Campos Lins (1999), a associação entre produção de conhecimento e ação tem uma longa tradição, que passa, por exemplo, por Charles Sanders Peirce, Gaston Bachelard e Gerard Vergnaud. Aqui, particularmente, seguimos mais de perto as indicações de Peirce, sendo nossa caracterização de "concepção" tributária daquela de "crença” de Alexander Bain, a partir da qual também o filósofo americano constitui seu Pragmatismo.

Nesse contexto, diríamos que as frases que repetimos sobre nossas concepções podem deixar nubladas essas nossas concepções. Ainda assim, a ação de dizer tais frases, a enunciação - ela própria - e nosso hábito de reproduzi-las incessante e intensivamente, dão-nos indicativos - insistimos - do nosso desejo de inscrição numa certa comunidade, do nosso desejo de sermos reconhecidos como membros de um grupo que constituímos e mantemos com nossos discursos.

É na ação efetiva que as práticas podem ser desveladas. Muitas pesquisas partem do pressuposto inverso: as concepções podem ser conhecidas a partir do discurso que promovemos sobre elas, e enunciações dessa natureza guiam - natural, linear e efetivamente - práticas. Fosse assim, se nossos mantras gerenciassem efetiva e diretamente nossas práticas, como teríamos, ainda, de modo hegemônico, as práticas de manutenção do quadro de fracasso que, em relação ao ensino e aprendizagem de Matemática, esses mantras via de regra condenam?

Constituídas num (e constituindo um) processo dinâmico de inserção no mundo, as concepções são aqui tomadas como fluidas, de difícil configuração, de estrutura vaga. Debater-se com isso é uma atitude vã. Querer fixar o dinâmico, dizer o indizível, é projeto para muitos quixotes e, ainda assim, como convém a quixotes, também ele um projeto vão. Enfrentar uma pesquisa que tem como pressuposto a instabilidade de seu tema, por outro lado, tem características incrivelmente positivas: essa postura nos obrigará a desprezar toda a forma de investigação concebida como definitiva, nos obrigará a abrir mão de todos os resultados tidos como inquebrantáveis, a abandonar, em suma, toda crença numa verdade estável, inquestionável e perene. Será preciso, portanto, redefinir nossas crenças sobre verdade e falsidade.

\section{Dúvida, verdade e hábito}

Ao homem, a dúvida é um estado de espírito natural, mas incômodo. Para Peirce 
(1998), em vez de querermos "saber a verdade" para ultrapassar a dúvida, bastar-nos-ia criar um estado-de-crença (ou um amalgamado de concepções, diríamos nós) que nos mantivesse afastados da dúvida. As concepções não são meras consciências momentâneas, elas são hábitos mentais que duram algum tempo (essa, portanto, a zona de estabilidade pela qual procurávamos) e são satisfatórios - como qualquer outro hábito - até que uma surpresa ocorra e comece a dissolvê-los, preparando o terreno para um outro hábito. A dúvida - ou mais propriamente a dúvida-genuína, aquela de que somos conscientes e da qual pretendemos nos afastar - não é, portanto, um hábito, é sua privação.

Peirce (1998) distingue a dúvida da crença/concepção em três pontos: existe uma diferença entre a sensação que caracteristicamente acompanha a dúvida (desejar fazer uma pergunta) e aquela que caracteristicamente acompanha a crença (desejar fazer um julgamento sobre algo); a sensação da crença é uma indicação mais ou menos segura de que, em nossa natureza, está sendo estabelecido algum hábito que determina nossas ações (a dúvida nunca tem tal efeito); a dúvida é um estado de insatisfação do qual lutamos para nos livrar, visando a passar para o estado da crença.

A crença é um estado calmo e satisfatório que não desejamos evitar ou trocar por uma crença em outra coisa. lsso é um ponto importante: a dúvida-genuína é um estado irritante, de insatisfação. Não dá nenhum indicativo para a ação, nenhuma informação de procedimento. Considerando que não existe no mundo verdade absoluta ou um eterno estado agradável da mente, sempre que o mundo não faz sentido, a dúvida novamente aparece pedindo ao homem que crie ou altere suas crenças, desafiando-o a mover-se para outro estado de crença. A esse processo, Peirce (1998) denominou "a fixação da crença”.

Os humanos vivem em um mundo de alterações e os hábitos nos quais suas "verdades" estão enraizadas, dando regras para a ação, são freqüentemente desafiados e confe- ridos. Tanto maior será nosso autocontrole quanto mais estáveis forem essas verdades que se mantêm como referenciais seguros. Em outras palavras: no movimento de fixação das crenças, gradualmente, nossa autocensura torna-se autocontrole. Seguindo por esse caminho, somos levados ao que se tem chamado "a máxima pragmática”:

Considere quais efeitos (que devem ter resultados práticos) concebemos como tendo o objeto de nossa concepção. Nossa concepção desses efeitos é o todo de nossa concepção do objeto. (Peirce, 1998)

A sentença, convenhamos, não é simples em sua enunciação. Entretanto, ela pode ficar consideravelmente mais clara se seguirmos um exemplo dado por J. P. Murphy em seu livro Pragmatism: from Peirce to Davidson, de 1990:

- Consideremos quais os efeitos (em suas relações práticas) julgamos ter hardness ${ }^{\prime}$. As respostas nos farão construir nosso conceito de hardness.

- não se deixa agredir por muitas outras substâncias (se for um objeto como uma pedra, mas se for uma cadeira...);

- não se pode ficar nela de modo confortável por muito tempo (se for uma questão...);

- não são muitas as pessoas que, quando expostas a ela, têm a resposta correta (mas se for um nó...);

- não muitas pessoas estão hábeis a desatá-lo num curto período de tempo (mas se for um problema...);

- não há muitas pessoas que possam resolvêlo em curto período de tempo (ou se for um trabalhador...);

- não há muitos de seus colegas que trabalhem melhor que ele (mas se for uma chuva...);

- não há muitas chuvas nas quais tanta água caia em tão curto tempo... e, assim continua-

1. As palavras hardness e hard (em tradução literal "dureza" e "duro"), e seus decorrentes usos, se traduzidos, prejudicariam, segundo nosso ponto de vista, a compreensão da intenção inicial do exemplo de Murphy. 
ríamos para uma tarefa hard, uma queda hard, uma peça de hard luck, um tratamento hard, uma feição hard, um inverno hard, um sentimento hard etc.

Assim, de acordo com Peirce (1998), para abordarmos as concepções, precisamos determinar qual hábito de ação elas produzem, pois o significado do pensamento está intimamente relacionado aos hábitos que ele permite criar.

A partir dessa constatação - e por concordar com ela - um modo de tratamento sistemático ao tema "concepção" nos surgiu: para conhecer e tentar compreender quais as concepções de alguém (digamos, por exemplo, dos professores de Matemática) sobre algo (digamos, por exemplo, a Matemática, o ensino e a aprendizagem de Matemática), é fundamental empregarmos uma "abordagem indireta".

\section{Abordagem indireta, alternativas utópicas}

Abordagem indireta: auscultar, por exemplo, as concepções dos professores de Matemática acerca da Matemática, interpelando-os não sobre essas concepções, mas sobre suas práticas. Não se trata meramente de "desconfiar" daqueles agentes dos quais queremos conhecer as concepções supondo que falsearão "a verdade" se interrogados diretamente sobre elas. Trata-se de buscar a descrição de algo (um ambiente, uma postura, uma estratégia, uma abordagem), cuja manifestação ocorre na prática efetiva, cotidiana, buscando configurar um ambiente de ação direta, familiar, confortável e seguro, em que tais concepções são efetivamente implementadas, um "espaço" de certo modo mais livre, menos aprisionado naquela teia de mantras oficiais que tendemos a entoar. Também não adiantaria, portanto, segundo essa abordagem, solicitar dos agentes uma reflexão sobre suas práticas (essa reflexão, ela própria, muito freqüentemente inoculada do germe discursivo gerenciado pela comunidade): a intenção é coletar relatos sobre a práti- ca e, se possível, acompanhar a efetivação dessa prática relatada. Ressalte-se que também o acompanhamento da prática não deve ser feito meramente com a intenção de comparar o relato à "realidade" da prática, mas para sentila, segundo os óculos perceptuais do pesquisador, no frescor do momento em que ela ocorre, até para que, munido dessas informações, outros elementos possam ser invocados quando coletando ou reformulando o relato sobre a prática. A coleta de depoimentos, se nos basearmos nisso, pode ser concebida como um campo de embate, ainda que seja um embate relativo, dada a importância da interlocução que permitirá ao pesquisador conhecer uma experiência que não é a sua. Um embate negociado, digamos.

Ainda que a discussão sobre o privilégio da prática sobre o discurso acerca das concepções seja tema que, do ponto de vista filosófico, exija maiores e mais profundas investigações, lembramos que, neste texto, estamos tão somente discutindo uma forma, uma estratégia, um protocolo de pesquisa que viabilize a compreensão das concepções. Mantras podem ser entoados em qualquer tempo e espaço, inclusive quando relatamos nossas próprias práticas (e não só, repetimos, quando falamos sobre nossas concepções). 0 que indica, pois, que devemos estrategicamente privilegiar a prática? O simples fato de que os depoimentos são coletados por alguém investido (ou supostamente investido) do discurso acadêmico, do "discurso competente" - o pesquisador, também já chamado por aqueles que trabalham na interface Educação-Psicanálise de "sujeito-suposto-saber", tanto como o é o professor para seus alunos - carrega potencialmente uma limitação, manifestada na fala do depoente. Uma limitação verificada de modo muito mais "natural" e direto quando estamos falando sobre as concepções (que, de certa forma, chamam à cena os mantras, as posições tidas como mais adequadas, melhores, mais sábias) que quando estamos relatando - ou assistindo, in loco as práticas dos entrevistados: a necessidade ou 
desejo de ser reconhecido pelo outro, de estabelecer uma interlocução na qual ambos se sintam reconhecidos como membros de uma mesma comunidade. lsso pode justificar - ainda que não fundamente, convenientemente ou em profundidade - o enfoque na prática para que o pesquisador possa auscultar as concepções de seus depoentes.

Obviamente são tênues as linhas que separam, nessa abordagem, desejo de conhecer e mera desconfiança, mas restará ao pesquisador cuidar tanto quanto possível para evitar o cerceamento, o julgamento prévio, a comparação ingênua. Caberá também ao pesquisador reconhecer-se como portador de óculos (sociais, teóricos, vivenciais) através dos quais encaminhará a pesquisa, seja coletando depoimentos, acompanhando práticas, analisando as informações vindas do campo ou sistematizando e divulgando suas compreensões. Não há neutralidade na pesquisa. A responsabilidade pela trajetória de investigação é essencialmente do pesquisador, não podendo ser diluída ou transferida - como pretendem abordagens "clássicas" - para o método ou qualquer outro recurso. As verdades constituídas por esse pesquisador são dinâmicas, fluidas, relativas a um certo momento, confinadas a uma certa comunidade, a certos espaços, a determinados contextos e depoimentos.

Em artigo (Garnica e Fernandes, 2002) publicado por mim e Déa Nunes Fernandes, pesquisadora maranhense, já afirmávamos a necessidade de abandonar a ilusão do geral, do global, do indiscriminado. Buscávamos, ao contrário, defender a criação de "campos de experimentação" nos quais fosse possível, como fontes de resistência, o exercício de dinâmicas alternativas (ainda que particulares e, algumas vezes, até singulares). Para isso, apoiávamo-nos no que Boaventura Souza Santos (2000) discute acerca do momento atual, fixando, para isso, o conceito de "transição paradigmática" que rege nosso presente, um ambiente de incertezas, complexidade e de caos que repercute nas estruturas e nas práticas sociais, nas instituições e nas ideologias, nas representações sociais e nas inteligibilidades, na vida e na personalidade. E repercute, muito particularmente, tanto nos dispositivos da regulação social quanto nos dispositivos da emancipação social. Um momento no qual não há agentes históricos únicos nem uma forma única de dominação. $\mathrm{Ou}$ seja, são múltiplas as faces da dominação e da opressão, e sendo múltiplas essas faces, são também múltiplas as resistências e os agentes que as protagonizam ou podem protagonizálas. Santos acredita que, na ausência de um princípio único, não é possível reunir todas as resistências e agências sob a alçada de uma grande teoria comum. 0 "novo" no contexto atual, são as classes dominantes se desinteressarem do consenso, tal é a confiança que têm na inexistência de alternativas às idéias e soluções que defendem. Por isso, não se preocupam com a vigência possível de idéias ou projetos que lhes são hostis, já que estão convictos da irrelevância e da inevitabilidade do fracasso desses projetos. Com isso, a hegemonia transformou-se, passou a conviver com a alienação social, e em vez de assentar-se no consenso, passou a assentar-se na resignação.

Tal situação faz com que surja a necessidade de um "pensamento alternativo de alternativas", a necessidade de cultivar outros discursos e novas práticas. Segundo Foucault (1977), não existem práticas inerentemente libertadoras ou repressivas, pois qualquer prática é cooptável e qualquer prática é capaz de tornar-se uma fonte de resistência. Acreditamos na possibilidade de busca de um discurso alternativo que seja adequado ao momento; que seja tanto ponto de resistência quanto marco de estratégias opostas ao exercício das práticas vigentes; um discurso em que a teoria e as práticas julgadas subversivas estejam juntas. Visa-se a um discurso-ação preocupado em desvelar as formas de hegemo-nia (sociais, econômicas, culturais) no interior das quais as verdades das práticas funcionam e em que, tidas como "naturais", são julgadas "necessárias" e, portanto, "legítimas" para extrapolarem o território em que tais verdades são criadas e mantidas. 
E não se trata de esperar que esse discurso alternativo torne-se o regime da verdade dominante. Assistimos hoje a uma crise importante nos discursos que, regendo a educação, se apoiavam na crença e na esperança de que as políticas, os currículos, as instituições e as práticas pedagógicas poderiam colaborar ordenadamente para a obtenção, de maneira racional, de fins seguros com validade indiscutível, alerta-nos Sacristán (1999). Trata-se, então, de acreditar que é possível, mesmo dentro dessa estrutura, o aparecimento de um pensamento que reconheça a existência do discurso atualmente dominante e que se contraponha a ele sem a utopia de acreditar que conseguirá derrubar sua hegemonia. Trata-se, portanto, de agir sem a esperança de que esse discurso se torne "a" verdade, sem pretender que ele seja "o" correto e "o" desejável por todos. Um esperar sem esperança. A esperança, já nos dizia Boaventura Souza Santos (2000), não reside num princípio geral que providencia um futuro também geral; reside, sim, na possibilidade de criar campos de experimentação nos quais seja possível resistir localmente às evidências da inevitabilidade, promovendo com êxito alternativas que parecem utópicas.

\section{Um exercício}

Munidos dessas compreensões, lançamonos, Letícia Maria Cordeiro de Campos Giani e eu, como orientador, à tentativa de compreender as concepções de professores de Matemática acerca da Matemática e seus entornos educacionais. Esse projeto partiu de observações que a autora fez em seu próprio cotidiano escolar, percebendo que muitos professores sentiam - e expressavam - dificuldades ao trabalhar com livros didáticos nos quais os conteúdos matemáticos não eram ordenados exclusivamente segundo critérios formais estáticos, mas organizados segundo visões e intenções assumidamente alternativas e interdisciplinares. A partir dessa constatação, estabelecemos, de início, um foco para a pesquisa: o livro didático como o elemento a partir do qual as concepções dos professores poderiam ser buscadas. Pretendíamos, portanto, investigar onde, ou em que, a dificuldade dos professores com textos didáticos ditos "alternativos" poderia estar radicada. A intenção da investigação e a forma de desenvolvê-la foram se constituindo em trajetória como ocorre, na verdade, com qualquer pesquisa. Em meio a uma série de leituras iniciais de fundamentação, aquele primeiro foco foi ainda melhor configurado: buscaríamos conhecer e compreender algumas das concepções dos professores de Matemática usando, como via indireta, o processo de escolha dos manuais didáticos, com o que foi fixada a questão diretriz da investigação: "Quais critérios o professor efetivamente faz valer quando da escolha de livros-texto e quais concepções de Matemática e de seu ensino e aprendizagem tais critérios desvendam?". Com o título Concepções de Professores de Matemática: considerações à luz do processo de escolha de livros-texto, o trabalho foi finalizado, apresentado e aprovado como dissertação de mestrado. É esse estudo o exercício de investigação acerca das concepções de professores que apresentamos a seguir.

Dez professores de Matemática com experiência docente em escolas públicas estaduais e municipais foram entrevistados para compor o quadro de referência empírico a partir do qual buscariamos compreender algumas das concepções destes, isto é, aquelas que, sob nosso ponto de vista, poderiam ser articuladas a partir dos critérios que eles faziam valer, efetivamente, quando escolhendo - e utilizando - textos didáticos para suas aulas. As dez entrevistas foram gravadas e transcritas. Ao processo de transcrição, seguiu-se outro, mais elaborado, ao qual chamamos "textualização".

A transcrição é uma fase de gravação da oralidade. Esse momento justifica-se por ser a oralidade evanescente - como o são todos os discursos em estado nascente -, do que decorre a necessidade de ser retida, fixada, para viabilizarmos, de maneira operacional, a negociação dos significados que, como processo de análise, dar-nos-á chaves para a compreensão 
daquilo que tematizamos. No entanto, a gravação não é de todo um processo mecânico, que só traga problemas de natureza prática: é preciso lembrar que toda transcrição é, já, uma primeira interpretação na perspectiva da escrita. Ainda que extremamente cautelosos durante os momentos de gravação, percebemos que alguns dos depoimentos estavam extremamente truncados e seriam de difícil compreensão no domínio da escrita (afastada a situação face-aface da interlocução entrevistador-entrevistado, certos sinais próprios da comunicação humana, como a gestualidade, por exemplo, perdiam-se, inviabilizando - ou dificultando sobremaneira - a interlocução leitor-autor). Com o procedimento da textualização - bastante usual em História Oral -, pudemos ultrapassar esse problema. A textualização é um processo de rearticulação discursiva, propositalmente realizado pelo pesquisador a partir do texto gerado pela degravação. Um procedimento de deteç̧ão e preenchimento de lacunas, de exclusão de vícios da oralidade, de reordenação - reorganização - do relato. Tantos mais recursos poderão ser chamados à cena quanto mais lacunares e truncados forem os depoimentos coletados ou maiores forem as habilidades literárias do pesquisador. E embora tal procedimento cumpra certa função estética retrabalhar o texto tornando-o mais fluente -, sua função precípua é de natureza epistemológica: permitir tanto quanto possível, na trajetória de rearticulações, exclusões e complementações, a compreensão dos significados que no texto o depoente esforçou-se por constituir. Uma função inequivocamente aliada àquela própria ao exercício da leitura, que também visa à aproximação, à familiarização. Ambas, textualização e leitura, são esforços próprios de um exame hermenêutico.

Todo o processo de textualização - é importante salientar - é feito com o depoente, que checa cada uma das alterações a que se procedeu, estabelecendo e autorizando a versão na qual estará enraizado todo o processo de análise subseqüente.

Terminadas as textualizações, procedeu-se a um momento da análise que chamamos de "análise bruta", um processo sem amarras teóricas prévias, sem parâmetros pré-definidos: no horizonte, somente as impressões iniciais que tivemos ao trabalhar com os depoimentos e, como resultado desse processo, um registro que deveria ser necessariamente reelaborado. Tal reelaboração ocorre no momento seguinte, quando começamos a detectar convergências e divergências entre os depoimentos - e, por vezes, até pontos divergentes acerca de um mesmo objeto ou situação dentro de um mesmo depoimento. Esses pontos - que obviamente exigem atenção e nada mais são que elementos de significação latente que o pesquisador trará à tona segundo sua própria perspectiva - foram agrupados e resultaram no que chamamos "unidades de análise", cada uma delas assinaladas em rubricas específicas para serem, em seguida, analisadas à luz de uma ampla bibliografia disponível acerca dos temas que elas próprias levantavam. Desse modo, pudemos perceber algumas faces de nosso objeto de investigação que são as que, sinteticamente, passamos a apresentar.

Os depoimentos dos professores indicam a existência de uma certa independência com relação à escolha dos materiais utilizados na execução de suas atividades docentes. Indicam ainda, em alguns casos, a valorização dos livros paradidáticos ou outros materiais que possam "enriquecer" suas aulas. De maneira geral, todos os professores parecem valorizar a pluralidade de textos. Esse procedimento, porém, pode estar respondendo à necessidade de contemplar um "programa internalizado" que nossos depoentes parecem possuir com relação ao ensino dos conteúdos matemáticos. Vários trabalhos, dentre eles, Freitag, Motta e Costa (1997), afirmam que o livro didático é, via de regra, o critério absoluto de verdade, o padrão de excelência a ser adotado na aula, e que muitos professores têm nele a única referência para a ação educativa, o que faz com que esse material assuma como que um autoritarismo. Essa nossa pesquisa levounos a uma compreensão alternativa: ainda que a presença dos livros didáticos seja marcante no cotidiano da maioria das salas de aula, os pro- 
fessores valem-se de outros materiais - que a eles são tão significativos quanto os manuais didáticos - , chegando a questionar algumas formas de apresentação dos conteúdos matemáticos. Assim, embora aceitemos que os livros didáticos sejam um material de referência para o trabalho do professor, acreditamos que esses professores possuem, como elemento mais forte do que os materiais utilizados em sala de aula, um "programa internalizado" que julgam verdadeiro, válido e necessário para desempenharem seu trabalho. A existência de uma vasta gama de livros didáticos que dão suporte à prática dos professores reforça a idéia de que os manuais, embora sejam uma referência fácil, adequada e segura, são instrumentos a partir dos quais esse "programa internalizado" age. Assim, é necessária uma variedade de materiais para que, disso, resulte uma abordagem ou um conjunto de materiais que seja justificado - e justifique - esse "programa internalizado". Além disso, parece-nos, ainda, que alguns autores gozam de uma certa "vantagem" em relação a outros por apresentarem os conteúdos matemáticos de maneira mais linear e com "encadeamentos lógicos”, com o que o "programa internalizado" do professor - uma manifestação clara de um aspecto de sua concepção - concorda.

Assim, embora ainda exista um forte vínculo entre o professor e o livro didático - situação que nos parece natural considerando o esse objeto como um dos instrumentos para a ação docente -, acreditamos que essa relação professor/manual didático não é linear e estática: comporta alterações para adequações. 0 professor submete-se ao livro didático, mas ao mesmo tempo, subverte essa submissão com a utilização de vários textos, buscando uma adequação ao que tem internalizado como sendo o correto. Compreensões dessa mesma natureza podem ser observadas nos resultados da pesquisa realizada por Golafshani (2002), da Universidade de Toronto. Nesse trabalho, a autora afirma que os professores com visões absolutistas com relação à Matemática, ao trabalharem seguindo as propostas do National Council of Teachers of Mathematics (NCTM) que apresentam a Matemática de maneira menos tradicional, tendem a realizar maiores ajustes nessas propostas na tentativa de tornar sua ação didática compatível com suas convicções, ou seja, eles não desprezam as propostas do NCTM: tentam adaptá-las às suas crenças. Também Tolentino-Neto (2003), ao estudar o processo de escolha de livros didáticos por professores de Ciências, observou que o primeiro elemento que os professores avaliam em um livro diz respeito à adequação das propostas desse livro às suas próprias dinâmicas em sala de aula.

Também a questão dos pré-requisitos constituiu uma outra dentre as unidades a partir das quais pretendíamos compreender as concepções dos professores. Nossa percepção com relação a esse tema, presente nos depoimentos coletados, é de que os professores muito freqüentemente avaliam/classificam seus alunos pela "falta" de alguns conteúdos matemáticos que, segundo seus pontos de vista, já deveriam estar "armazenados", "disponíveis para uso". Essa postura parece refletir a valorização da precedência lógica dos conteúdos, de sua linearidade e encadeamento tidos como indiscutíveis. Essa certeza quanto à necessidade de habilidades prévias e disponíveis para o desenvolvimento do currículo escolar implica, freqüentemente, a utilização de uma metodologia na qual as aulas são predominantemente expositivas. Não observamos, nos depoimentos, nenhum questionamento com relação à validade ou não deste "armazenamento" de conteúdos: o aluno, segundo o professor, deve ter os conteúdos anteriores disponíveis, sendo essa a única forma de sucesso na apreensão de novos conceitos.

Não são poucos os trabalhos - entre eles podemos citar Lins (1999) e Serrazina (2005) que explicitam e questionam essas práticas sem reflexão que, a nosso ver, induzem à avaliação pela "falta" . A ausência de reflexão pode nos levar a atos fundados em posturas adotadas como válidas e verdadeiras meramente por refletirem uma posição amplamente aceita, mantida e difundida. São, portanto, atos ideologicamente coniventes com a atual situação do ensino. 
Um dos discursos - aos quais anteriormente chamamos "mantras oficiais" - que mantém essa prática é o da apregoada necessidade de defender e exercer a interdisciplinaridade. Tal discurso, em contraponto, manifesta a existência de uma compartimentalização do currículo escolar, no que se incluem os conteúdos matemáticos e as práticas de sala de aula. Esses posicionamentos podem ser observados com os recortes de alguns dos depoimentos, nos quais o professor afirma "não entender claramente qual é objetivo do livro adotado ao intercalar atividades de geometria e conteúdos matemáticos", achando "complicado trabalhar geometria e matemática ao mesmo tempo, pois ao parar para trocar de assunto a cabeça do aluno fica bagunçada, por isso a escola particular não mistura geometria aos conteúdos”. Essa compartimentalização, defendida como necessidade da interdisciplinaridade, parece ser incompatível com uma proposta interdisciplinar. Deve-se ressaltar, no entanto, que não fica claro, com a leitura dos depoimentos, se a valorização da interdisciplinaridade está fundamentada em literatura específica, em experiências prévias ou se faz parte de um "modismo", essa forma de desenraizamento tão usual no mundo contemporâneo. De certo, tem-se que todo o processo de análise para a escolha de livros didáticos, nas escolas nas quais trabalham os professores-depoentes, ocorreu internamente, em grupos de professores de mesma disciplina, sem intervenções externas, uma desatenção para com o necessário cruzamento de perspectivas que a interdisciplinaridade que promovem não só recomenda, mas exige.

0 apelo à contextualização dos conteúdos ensinados nas aulas de Matemática - esse outro mantra - também ocorre na maioria dos depoimentos por nós coletados. Segundo os professores, "não podemos mais ensinar os conteúdos matemáticos se estes não estiverem vinculados aos acontecimentos cotidianos dos estudantes e da sociedade", um apelo vinculado à própria motivação do aluno: a contextualização "promoveria o interesse pelos conteúdos”, com o que fi- caria "garantida a aprendizagem". 0 uso de livros paradidáticos - que segundo Dalcin (2002) inicialmente tiveram como um de seus objetivos introduzir, de maneira mais rápida, no ensino da Matemática, algumas mudanças para uma de "modernização" da disciplina -, parece ser, além da tentativa de dar vazão à interdisciplinaridade, um indicativo dessa tentativa de contextualização dos conteúdos, já que esses materiais vinculam, muitas vezes, o conteúdo matemático aos fazeres humanos, cotidianos ou não. Os paradidáticos são intensa e insistentemente defendidos pelos depoentes

Outra característica marcante nos discursos dos professores é a supremacia do específico com relação ao pedagógico. Os professores deixaram claro, em seus depoimentos, que buscam por livros ou outros materiais que contemplem a transmissão dos conteúdos matemáticos, utilizando-se, para isso, de exercícios e outras atividades práticas. Esses conteúdos matemáticos que os professores parecem buscar nos livros didáticos de que se utilizam - e acrescentamos: o encadeamento desses conteúdos e a forma de abordagem adequada a eles - são os mesmos que julgamos compor seu "programa internalizado". Não percebemos, nos discursos dos professores, a busca por abordagens de ensino alternativas tanto quanto não percebemos disposição em tematizar "avaliação". O livro didático é, via de regra, ancoragem puramente didática, totalmente apartada do universo das questões pedagógicas. Essa compreensão reforça compreensões advindas de outros trabalhos sobre concepções de professores de Matemática: escapa à prática de sala de aula - e, portanto, aos seus atores e agentes - a diferenciação entre pedagogia e didática. E mais, a ausência do exercício pedagógico nas aulas de Matemática afirma e reproduz uma doutrina segundo a qual o conteúdo matemático é, por excelência, um locus a partir do qual e para o qual todas as ações devem ser

2. A expressão "leitura pela falta" e uma discussão dessa postura face a uma possível e desejável "leitura positiva" são temas centrais do trabaIho de Lins (1999). 
conduzidas. A ausência de preocupações em relação à didática - que na fala de nossos depoentes, em princípio, não se revela, visto serem seus discursos plenos de frases que advogam pela necessidade de articulações, interdisciplinaridades e contextualizações - e à pedagogia é, em suma, a "forma de ação" - ou o modo de pensar que se manifesta em ação - mais presente, e nos conduz às negligências com o domínio do pedagógico, com suas danosas e já conhecidas conseqüências. A preocupação "apenas" com a didática - o que parece poder ser compreendido a partir dos depoimentos dos nossos professores está enraizada no apego a procedimentos técnicos desvinculados de reflexões acerca da natureza educacional de suas intervenções.

Como outro elemento para constituir nosso cenário acerca das concepções dos professores de Matemática - vistas essas concepções a partir dos modos como esses professores relacionam-se com os livros didáticos -, pontuamos que os depoentes parecem não valorizar ao menos, não fazem referência alguma em relação a esse tema - a formação ou origem dos autores dos textos que utilizam. Julgamos que conhecer a origem dos manuais, a situação, o momento, as circunstâncias em que foram produzidos, o percurso profissional e acadêmico por que passaram seus autores, é de extrema importância no momento da escolha desse material - e conseqüentemente do seu uso em sala de aula -, tendo em vista que, embora existam as exigências do mercado editorial, o conteúdo de qualquer livro "carrega" consigo muitas das visões de mundo de seus autores, seus históricos de produção e de envolvimento com a comunidade de educadores matemáticos. Alguns professores afirmam - talvez respondendo a essa negligência quanto ao entorno de produção do material que utilizam - não haver diferenças entre os livros: o que difere é, "apenas", a maneira de o autor apresentar os conteúdos. Conteúdo, portanto, é conteúdo. Nisso manifesta-se uma das mais arraigadas concepções dos professores em exercício: conceber a Matemática como um conjunto de objetos, independente das práticas de tratamento a esses objetos.

Nessa trajetória de compreensões e interpretações, devemos registrar as referências que os professores fazem acerca dos "problemas" que enfrentam durante a execução de suas atividades docentes. Pudemos categorizar tais "problemas" em dois grandes grupos: os da vertente técnica e aqueles de vertente educacional, uma categorização provisória e apenas operacional, pois certamente equivocada em sua essência, visto que tais vertentes, no universo dessa investigação, não são disjuntas. Problemas técnicos são aqueles originados dentro da escola (direção, coordenação, professores etc.) e na distribuição de livros didáticos pelos órgãos competentes. Já os problemas educacionais são aqueles que têm sua origem ou nas normas e determinações da Secretaria da Educação (SE) - que, num plano amplo, gerenciam o cotidiano das escolas - ou em espaços extra-escolares, do que é caso marcante o posicionamento da família com relação à educação de seus filhos.

Embora o Programa Nacional do Livro Didático (PNLD) avalie os livros didáticos e divulgue esses resultados para que os professores façam a indicação de duas opções para a compra dos manuais a serem utilizados pelos alunos, segundo o depoimento dos professores, esse processo possui, ainda, falhas sensíveis. Alguns professores citam um atraso no recebimento desse material, enquanto outros criticam o recebimento de livros desconhecidos daquele grupo de professores que, de um modo ou outro, fez suas escolhas e indicou claramente duas opções de compra. Alguns depoentes relatam, considerando suas experiências, que apenas os professores efetivos têm a oportunidade de trabalhar com os livros escolhidos. Por não terem suas classes garantidas em uma mesma escola, submetendo-se, anualmente, a um processo de atribuição de aulas que ocorre segundo a pontuação adquirida no decorrer de sua vida profissional, muitos professores participam das escolhas em uma determinada escola e realizam seu trabalho, no ano seguinte, em 
outra. Outra constatação é a de que os professores relutam em aceitar alguns posicionamentos e determinações da Secretaria da Educação, da direção e da coordenação escolar, ou mesmo das famílias de seus alunos: uma subversão?

As concepções podem atuar, por um lado, como um filtro que estrutura o sentido que damos às coisas e, por outro lado, como bloqueadoras em relação a novas realidades, limitando nossas possibilidades de atuação e compreensão. Os conflitos entre as concepções enunciadas e as práticas efetivadas podem estar na essência das divergências existentes entre os professores e os órgãos responsáveis pelas legislações a que é submetida a ação docente. Para os depoentes, é certo que os problemas educacionais emergem do distanciamento entre suas crenças e as determinações a que seu trabalho é submetido. Observa-se ainda que os professores não julgam como "suas" essas determinações, ou seja, queixam-se de que "nunca são ouvidos”, reagindo a elas com uma certa desconfiança e revolta.

\section{Achados}

Esse é um achado breve, pois é decorrência de tudo que até aqui já foi explicitado: uma amarração.

Embora uma pesquisa seja uma atividade sempre em processo por nos dar motivos para outras inquietações e por sempre poder ser retomada à luz de outros procedimentos, outros fundantes, outras constatações, ainda assim, irremediavelmente aberta, podemos dar aos nossos exercícios de investigação arremates parciais, sempre sujeitos a reescrita, a outras considerações, atualizações, novas e mais profundas compreensões. Parece-nos natural que, ao final de um trabalho que tem como tema as concepções dos professores de Matemática, o leitor pergunte-se: afinal, quais são essas concepções? 0 que o pesquisador, em sua investigação, pôde detectar ou conseguiu compreender sobre elas?

Não é possível - e a isso pensamos ter respondido ao apresentar nossas fundamenta- ções - pontuar, decisiva e objetivamente, tais concepções, dado que elas estão atreladas às práticas nas quais se manifestam, e são dinâmicas, alteram-se, ocorrem sob discursos vários, em ações e situações às vezes diferenciadas, alternativas; às vezes conservadoras. Embora não se possa, objetivamente, listar as concepções dos professores, elas emergem de todo esse emaranhado de compreensões que, até aqui, pudemos vislumbrar. Podemos, entretanto, descrever, ainda que de modo aligeirado, algumas das manifestações mais freqüentes e aparentemente mais "estáveis" - a partir das quais essas concepções se deixam perceber.

Embora os professores entrevistados falem em contextualizar os conteúdos matemáticos, em trabalhar de maneira interdisciplinar e em promover a interação dos alunos com os conteúdos estudados, a busca por materiais mais especificamente a busca por livros didáticos - que contemplem o que chamamos de “programa internalizado", é justificada pela necessidade de a apresentação dos conteúdos ter encadeamento lógico, linearidade e, em alguns casos, ser compartimentalizada. Ou seja, buscam por materiais que se aproximem da maneira pela qual a Matemática tradicionalmente vem sendo apresentada. Essa justificativa, além de outras práticas que o professor exercita em seu trabalho cotidiano, parece indicar que esse seu fazer, apesar das tentativas, permanece vinculado à concepção de que a Matemática é um conjunto de objetos organizados linear e seqüencialmente. Parece, ainda, permear os discursos e as práticas dos professores, a crença de que a Matemática é única, infalível e está isenta das transformações constantes, por vezes caóticas, às quais tudo e todos estamos sujeitos.

Coerente com essa concepção, embora exista a tentativa de fazer com que o aluno interaja com os conteúdos estudados e que estes sejam significativos a ele, o processo de ensino e aprendizagem ocorre tendo como parâmetro a certeza de que a apreensão de novos conhecimentos é fruto de atividades repetitivas, seqüenciadas e freqüentes, assim 
como da memorização de procedimentos. Mantendo-se a coerência, o ensino é baseado na suposta "transmissão de conteúdos", prevalecendo, por parte dos professores, a exposição como prática didática tida como mais eficiente: fala-se adequadamente para que o aluno aprenda adequadamente, como se o processo de comunicação fosse, também ele, tão linear e livre de interferências como se supõe ser o conteúdo a ensinar.

Consideramos, finalmente, que os discursos analisados indicam a permanência de uma concepção mais fortemente tradicionalista do que alternativa. Tanto o conteúdo a ser ensinado quanto as abordagens mais adequadas para tal seguem um curriculum internalizado, impermeável a alterações, estabelecido pelo professor a partir das experiências que ele considera relevantes, adequadas, corretas, positivas. Aos alunos, resta a passividade frente ao processo de ensino e aprendizagem, uma passividade que o professor, segundo seus discursos, condena e pretende evitar.

Dar respostas - principalmente respostas tidas como definitivas - não nos é possível nem é nosso objetivo. Se pensássemos em conclusões e "fechamentos" estáticos, estaríamos contrariando os pressupostos assumidos anteriormente, que inscrevem este trabalho numa abordagem qualitativa de pesquisa. Preferimos a trajetória à chegada. É a trajetória para compreender quais são e como funcionam as concepções dos professores que nos permite algumas compreensões e nos dá poder de crítica, mesmo que não possamos enumerar quais são essas concepções nem descrever de forma definitiva seu funcionamento, como podem querer os que não compartilham das nossas opções.

\section{Referências bibliográficas}

DALCIN, A. Um olhar sobre o paradidático de Matemática. 2002. Dissertação (Mestrado)- Faculdade de Educação. Universidade Estadual de Campinas, Campinas, 2002.

FERNANDES, D. N. Concepções de professores de Matemática: uma contra-doutrina para nortear a prática. Dissertação (Mestrado)- Instituto de Geociências e Ciências Exatas. Universidade Estadual Paulista, Rio Claro, 2001.

FOUCAULT, M. Vigiar e Punir. Petrópolis: Vozes, 1977.

FREITAG, B.; COSTA, W. F.; MOTTA, V. R. 0 livro didático em questão. 3. ed. São Paulo: Cortez. 1997.

GARNICA, A. V. M. e FERNANDES, D.N. (2002). Concepções de professores formadores de professores: exposição e análise de seu sentido doutrinário. Quadrante: Revista de Investigação em Educação Matemática, Portugal, v. 11, n. 2, p. 75-98.

GOLAFSHANI, N. Teacher's conceptions of mathematics and their instructional practices. Disponivel em <http://www.ex.sc.uk/ $\sim$ Pemest/pome15/golafshani.pdf>. Acesso em: 2002.

HEIDEGGER, M. Basic Writings. New York: Harper, 1993.

LINS, R. C. Por que discutir teoria do conhecimento é relevante para a educação matemática. In: BICUDO, M. A. (Org.). Pesquisa em educação matemática: concepções \& perspectivas. São Paulo: Ed. UNESP, 1999. p. 75-94.

MURPHY, J. P. Pragmatism: from Peirce to Davidson. San Francisco: Westview Press, 1990.

PEIRCE, C. S. The colletcted papers of Charles Sanders Peirce. 8 v. Cambridge: Belknap Press of Harvard University Press, 1960-1966.

The essential Peirce: selected philosophical writings. 2 v. Bloomington: Indiana University Press, 1998.

SACRISTÁN, J. G. Poderes instáveis em educação. Porto Alegre: Artes Médicas, 1999. 
SANTOS, B. de S. A crítica da razão indolente: contra o desperdício da experiência. Para um novo senso comum - a ciência, 0 direito, e a política na transição paradigmática. São Paulo: Cortez, 2000.

SERRAZINA, L. Reflexão, conhecimento e práticas lectivas em matemática num contexto de reforma curricular no $1^{\circ}$ ciclo. Disponivel em: <http://www.educ.fc.ul.pt/docentes/jponte/fp/textos\%20_p/99-serrazina.doc>. Acesso em: 2005.

TOLENTINO-NETO, L. C. B. de 0 processo de escolha do livro didático de Ciências por professores de $1^{\mathrm{a}}$ a $4^{\mathrm{a}}$ séries. Dissertação (Mestrado)- Faculdade de Educação, Universidade de São Paulo, São Paulo, 2003.

Recebido em 12.04.07

Aprovado em 25.08.08

Antonio Vicente Marafioti Garnica é professor adjunto do Departamento de Matemática da Faculdade de Ciências UNESP - Bauru, e do Programa de Pós-Graduação em Educação Matemática - UNESP - Rio Claro. 